\title{
XLVIII. Strictures on Dr. Young's and La Place's theories of the tides. In a letter to Dr. Young
}

\section{Captain Waltr Forman R.N.}

To cite this article: Captain Waltr Forman R.N. (1823) XLVIII. Strictures on Dr. Young's and La Place's theories of the tides. In a letter to Dr. Young , Philosophical Magazine Series 1, 61:299, 219-228, DOI: $10.1080 / 14786442308644305$

To link to this article: http://dx.doi.org/10.1080/14786442308644305

里 Published online: 29 Jul 2009.

Submit your article to this journal $\lceil\pi$

Џll Article views: 2

Q View related articles ๘ 
XLVIII. Strictures on Dr. Young's and La Puace's Theories of the Tides. In a Letter to Dr. Young. By Captain Forman, R.N.

Sir,

I BEG leave to acknowledge the receipt of your letter, dated February 6th, 1823, in which I am informed, "that the Board of Longitude sees no reason to alter its sentiments respecting my theory* ; and that the Board considers it as unnecessary to give me the trouble of a personal attendance at any of its meetings."

Now, Sir, under correction, I submit, that, if the members of the Board of Longitude had really wished to ascertain whether my Theory of the Tides was well founded, their best plan would have been to have permitted me to have been present at the time of its discussion, in order to give me the opportunity of explaining those parts of it that might have required explanation, and of replying to any objections that might have been brought against it. This, Sir, would at least have looked like sincerity, and have taken from me all right to complain; but as you will neither afford me this opportunity of explaining my hypothesis, nor condescend to inform me upon what grounds you found your objections, the only alternative that is left me is to compare my theory with the one that is most in vogue at present; and if $I$ can make it appear, that the necessary and acknoroledged consequences of the latter are at variance with facts, I expect that the Board of Longitude will embrace the opportunity of proving its impartiality and love of justice, by pronouncing this theory to be ill-founded also.

I have now before me the first volume of your "Lectures on Natural Philosophy;" and as you have referred to La Place's opinions, without pointing out any material difference in your sentiments, it is fair to consider both theories as substantially the same; and consequently the same arguments that are sufficient to prove your theory ill-founded, must be equally efficacious when applied to the other. The grand feature in both your theories is, that the tides, which visit our coasts, and indeed all the coasts of the Atlantic, come from the Southern ocean; and the only difference in your opinions, at least so far as concerns the production of the derivative tides, is, that you suppose the original wave, from whence this tide is derived, moves at the rate of about five hundred miles an hour, and reaches the port of Brest about twelve hours after it has en-

* Which was teferred, by the Board of Admiralty, to the Board of Longitude, and pronounced by the latter to be ill-founded. 
tered the Atlantic; while La Place supposed that it required a day and a half to arrive at the same place.

It is the nature of fluids to press equally on all sides *; and, if a portion of its gravity should be taken away from the water in one part of the ocean, the pressure of the other parts will naturally (unless prevented) cause this part to be lifted up, until the superior gravity of the particles on one side be balanced by the greater quantity on the other. So far as I can understand you, for you are not very explicit, this principle forms the groundwork of both your theories: but, at all events, as water, under all circumstances, always falls down when it is deprived of its support, it must be clear that if neither the moon's attraction nor its centrifugal force can prevent water from falling, they cannot of themselves lift water up; and, as you will not allow my principle of expansion to be an efficient cause, there is no other principle that can, in any way, account for the phenomenon.

You say "that if the earth were wholly flud, and the same part of its surface were alivays turned towards the moon, the pole of the spheroid being immediately under the moon, the Iunar tide would remain stationary, the greatest elevation being at the points nearest the moon and furthest from her, and the greatest depression in the circle equally distant from those points ; the elevation being, however, on account of the smaller surface to rohich it is confined, twice as great as the depression."

Now, Sir, I have already proved that the moon's attraction cannot lift the waters up, and you have declared that my principle of expansion is not "well founded." It is fair then to conclude that you account for the rise of those waters which have least gravity, by the pressure of those which have most; and I admit, that if the same part of the earth's surface was always turned towards the moon (but not otherwise), the pressure of the heavier particles would produce a fall on the one side and a rise on the other, which, added together, would be nearly, but not quite, equal to the proportion the loss of gravity bore to the depth of water. So far I admit this principle to be good; but I deny that the elevation will be greater than the fall; because, if the water be lifted up by pressure; it is evident that the rise on the one side will be no more than what is just sufficient to make room for the fall on the other. Let the curved line A B C fig. 1 . represent the surface of the ocean covering a whole quadrant of the earth's circumference.

* This, by the way, is caused by the elasticity, not the slipperiness, of their particles; for if it was not for this principle of elasticity, the only effect that could be produced by an increased gravity of the waters would be to bury their lower parts decper in the bed of the occan. 
Now if the waters between $B$ and $C$, in consequence of their superior gravity, fell down to the dotted line $\mathrm{B} c$, there would necessarily be a corresponding rise on the opposite side of $B$
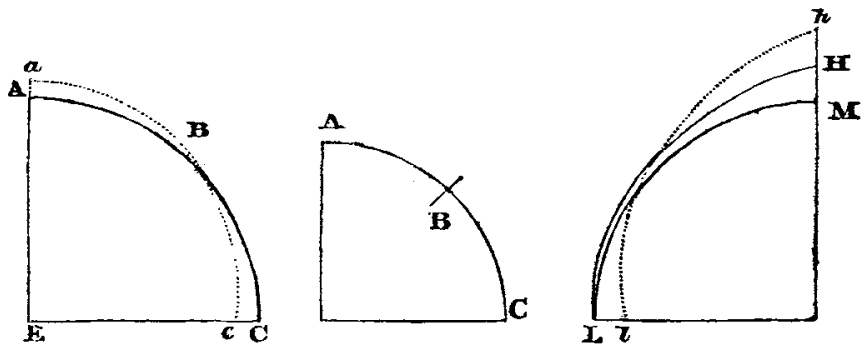

to make room for this depression; but, as the area $a c \mathrm{E}$ is equal * to the area A C E, it is evident that this rise would not exceed the height of the dotted line $\mathrm{A} a$, which is just equal to the fall $\mathrm{C} c$.

Now, Sir, if you meant to be understood that the waters are drawn up simply by the power of the moon's attraction, you are bound to show how it happens that the moon's attraction has power to lift the waters up, when it has not power to prevent them from falling: if you meant that the waters are lifted up by the expansion of their own particles, you ought, in justice, to have admitted my theory to be true; and if you meant that they are lifted up by the pressure of the heavier particles, independent of expansion, your principle will not account for the elevation being greater than the fall; and I beg you to keep this latter fact in mind, because I shall presently make use of it as an argument to prove the superiority of my theory over yours.

But, whatever may be the principle by which you account for the rising of the tides, you have plainly stated as facts, that, from some cause or other, there is an elevation produced in the Southern Ocean of forty inches, and a fall of twenty; that this trifling elevation of only forty inches sends a wave into the Atlantic, at the amazing rate of five hundred miles an hour, which finally raises the tides on our shores two or three times as high as the source from whence they are derived. Now, as water is never known to rise above its source, I cannot understand how a rise and fall in one place of only five feet can produce a rise and fall in another place of sixteen or eighteen

* In fact it is rather more; but as this difference, in a radius of four thousand miles with a fill of only a few fathoms, would only amount to an infinitely small fraction, the two areas may be considered as essentially the same.

feet ; 


\section{Capt. Forman on Di, Young's and La Place's}

feet; and especially at the distance of more than four thousand miles, which alone, one would naturally suppose, would be quite sufficient to exhaust the whole force of the pressure. Be this, however, as it may, it is clear that if, as you suppose, the original tide does come from the Southerri Ocean, it must visit. the southern coasts of the Atlantic before it does the northern; and the following extracts from a Tide-table evidently prove that the very reverse of this is frequently the case.

Times of High water on Fall and Change Days.

\begin{tabular}{|c|c|c|c|c|}
\hline Places. & Situation. & $\begin{array}{l}\text { Time. } \\
\text { H. x. }\end{array}$ & Lat. & Long. \\
\hline Sligo & Ireland & 645 & 5422 & 840 \\
\hline Butt of Lewis & Lewis Islands & 645 & $58 \quad 29$ & $6 \quad 12$ \\
\hline Balta & Shetland & 300 & 60 & 1 \\
\hline Bantry Bay & Ireland & 345 & 5135 & 1004 \\
\hline Cape Finesterre & Spain & 300 & 4256 & 917 \\
\hline Oporto & Portugal & 315 & 4111 & 8 \\
\hline Bayonne & France & 330 & $43 \quad 29$ & 1 \\
\hline Nantucket & America & 1203 & $40 \quad 43$ & 6950 \\
\hline Boston & America & 1130 & $42 \quad 24$ & 7103 \\
\hline Cape Canso & America & 830 & 4520 & 6055 \\
\hline Buttton's Island & America & 650 & 6935 & 6520 \\
\hline Entrance of Senegal & Africa & 1030 & 1553 & 16 \\
\hline Cape Blanco & Africa & 945 & $20 \quad 55$ & 17 \\
\hline
\end{tabular}

In every one of the ahove extracts, and I night easily have produced as many more, it is evident that the necessary and acknowledgred* consequence of your theory is at variance with facts; and I suppose you will allow, that a proposition which is at variance with facts cannot possibly be true. Making the proper allowance for the difference in their longitudes, it is high water at Balta as soon as it is at Bantry Bay, and at Bayonne even before it is at Oporto; and yet, if the tide did come from the southward, it evidently could not reach the two former places until it had passed the two latter. It is evident from this, that the tides in the North Atlantic Ocean do not come from the Southern Ocean; and, in order to anticipate every objection that can be brought against my theory, I shall now show that they are not produced by any pressure in the Atlantic Ocean, that may be occasioned by one portion of the waters being heavier than another.

Upon the principle of pressure and equilibrium, it is clear that twice the depth of ocean will make amends for the loss of

* "It sends a wave into the Atlantic, which is perhaps twelve or thirteen hours in it passige to the coast of France."-Sect Lecture xlvii. page 580 . 
half its breadth*; and if you really meant to account for the rising of the tides by pressure, it is wonderful that this idea never once entered your thoughts, as it would have saved you the necessity of supposing, that a wave or tide could move at the incredible rate of 500 miles an hour. But, at all events, it is very easy to prove that, if this principle will not produce a sensible rise of the tides, a greater breadth of ocean can do little more than add another cypher to the sum of nothing. Let A B C (fig. 2.) represent a quadrant of the earth's circumference, and $\mathrm{BC}$ the boundaries of the Atlantic Ocean, which is about $45^{\circ}$ broad. Now, upon the principle of pressure and equilibrium, if we suppose the moon to be vertical at $A$, there would be $a$ rise at $B$ and $a$ fall at $C$ exactly proportioned to the difference in their specific gravities; but all the while the moon was moving from $\mathrm{A}$ to $\mathrm{B}$, which would take about three hours, the waters at $B$ would remain stationary at the same height, because the specific gravities of the waters in the Atlantic Ocean, during the whole of this time, would necessarily bear the same proportion to each other, and consequently must produce similar effects. In three hours after the moon had passed $\mathrm{B}$, she would be vertical at $C$, and then it would be high water at $\mathrm{C}$ and low water at $\mathrm{B}$, and would continue so the next three hours; so that, if the tides were produced by the pressure of the waters within the Atlantic, they ought to remain stationary at high and low water for the space of three hours without any apparent rise or fall; and, as this phænomenon has never yet been observed, it is fair to conclude that the tides are not produced by pressure.

Here, perhaps, it will be argued, that if it be the nature of fluids to press the lighter particles upwards until the equilibrium be restored, there must necessarily be a rise and fall of the waters produced by pressure, and that these effects ought to be visible. To this I reply, that these effects are entirely prevented by the moon's motion. Let $A$ and $B$ represent two adjoining portions of water in the ocean, and suppose the spe-

* If we suppose any part of the ocean to be $90^{\circ}$ broad, twelve miles deep, and the waters at one extremity to be twice as heavy as they are at the other, there would necessarily be a rise of four miles at one end and a fall of four miles at the other; so that eight miles depth of heavy partieles might just miles at the other; so that eight miles depth of heav miles of those which had only half their weight. Now if we suppose the waters in this ocean to retain the same specific gravity, gradualty increasing from one end to the other, but that half the breadth was cut off, the waters at one extremity would only be one-half part heavier than the other extreme; and yet, if the ocean was twenty-four miles, or twice as deep, there would be a fall at one end and a rise at the other of more than four miles and three quarters, in order to restore the equilibrium; and consequently twice the depth of ocean will more than compensate for the loss of half its breadth.

cific 


\section{Capt. Forman on Dr. Young's and La Plcae's}

cific gravity of $A$ to be somewhat more than that of $B$. Now, if the moon stood still, there would necessarily be a fall of the waters at $A$ and a rise at $B$, until, in consequence of the increased quantity of the lighter particles and the diminution of the heavier ones, the weight of the two portions became exactly equal. But, in consequence of the moon's continual motion, the specific gravity of all the particles of water is continually changing, and consequently, the moment the particles at $\mathbf{A}$ begin to press upon $B$, the weight of $B$ becomes equal to the weight that $A$ possessed. at the time the pressure commenced; and though the weight of $A$, for some time at.least, is continually increasing, yet, as the weight of $B$ increases in the same proportion, the resistance on the one side will always be equal to the pressure on the other. Suppose a person to be continually throwing weights into one scale in order to lift up the other, .but that the weight of the opposite scale (no matter by what means) constantly increased in exact proportion with the power that was employed to lift it: does it not necessarily follow that the two scales, under these circumstances, must always preserve the same equipoise? And, by the same rule, so long as the moon continues to change its place, the resistance of the particles on the one side will always be equal to the pressure on the other. Fortunately, however, this fact does not rest upon mere opinion. There is a case almost precisely analogous, in which a much greater disproportion of pressure does not produce any sensible alteration in the relative position of the waters; and if the effect is not produced in this instatre, we have no right to conclude that it can be in the other. The earth moves in its orbit with a velocity equal to 68,000 miles an hour; and while it is pressing upon the waters before it with this annazing force, it is simply dragging the waters behind it by the power of its attraction. Now, if the same parts of the earth's circumference (supposing them to be water) were always before and behind the earth's track, there would no doubt be a fall of the waters. before and a rise behind, until the greater pressure of the waters before were counterpoised by the greater quantity of the waters behind. What is the reason, then, that this extraordinary pressure does not produce a rise and fall of the waters, but because the effect is entirely counteracted by the earth's revolving on its axis? Before those waters which are immediately before the earth's track can produce any effect by pressure upon their neighbours, they are removed to the very situation their neighbour's occupied the moment before, and are prevented from falling by the greature pressure of those particles which have just taken their places. Whether this reasoning be good or not, it is clear that this extraordinary pres- 
sure does not produce any sensible rise in the waters; and, as it does not, we have certainly no grounds to suppose that the comparatively trifling pressure occasioned by the moon's attraction is sufficient to produce a rise in the waters of several fathoms.

The phænomena of the tides in every respect are totally dissimilar to the effects that must necessarily be produced by pressure; and this fact alone, even if the impossibility had not been made good, would be quite sufficient to prove that the tides are not produced by pressure. I have also proved that your and Laplace's theories are at variance with facts, and therefore cannot possibly be true; and I shall now show, that the necessary consequences of my theory correspond in every particular with the phænomena that really take place in nature: and if all this, taken together, do not amount to a sufficient proof that my theory is true, I am at a loss to understand how any thing in philosophy can be proved, or why we should set a greater value upon the opinions of a Newton, than upon the wild and frantic conceptions of the most fanciful enthusiast.

As the sum of the expansion of a sufficient number of particles will amount to several fathoms, while the sum of the expansion of a very few will be imperceptible, my principle of expansion necessarily requires that there should be a sufficient depth of water in the neighbourhood of any projecting cape where the tide first makes its appearance, and that the moon should be vertical, or nearly vertical, over that place at the time of high water. Now, if it should be found that the time which my theory necessarily requires for the tide to arrive at the coast after it has been produced in this deep water, should, as far as we are capable of proving it, exactly correspond with facts, it will furnish a strong presumption that.my theory is true; and I am very willing to allow its reception to depend upon this proof.

It appears by the Tide-table now before me, that it is high water at the Land's End four hours and a half after the moon has passed the meridian. Now, if we suppose this tide to be produced at about two hundred miles to the south-west of the Land's End, the moon will be on the meridian at that place about sixteen minutes alter she has passed the meridian of the Land's End: and, supposing the ocean in this place to be seven or eight miles deep, and the pressure to move at the rate of about fifty miles an hour, it will take ten or twelve minutes afterwards for the tide to arrive at its full height. It would be high water then at this place about half an hour after the moon had passed the meridian of the Land's End; and, supposing the tide to advance at the rate of fifty miles an hour, which it does in the Channel, it would require just four hours Vol. 6I. No. 299. March 1823. If $f$ 
to reach the distance of two hundred miles, and consequently would be high water at the Land's End exactly at the time set down in the ride-table. Now if it should be found that, at the distance of more than two hundred miles from the Land's End, ships are in the habit of striking soundings, it would be evident that my theory was erroneous; but if they cannot get soundings in any part of the world, at those distances from the shore where my theory indicates the tides are produced, this circumstance will amount to a demonstrative prool that my theory must be true: for it is morally impossible that a false theory can always be right by chance.

Again, I have proved (fig. 1) that, if the waters were lifted up by pressure, the elevation would be equal to only the fall; whereas, you have acknowledged yourself, and the fact is easily proved, that it ought to be at least twice as great. Let us now see whether my theory of exparision will account for this phænomenon; and if it will, in what way cau you account for a false theory's corresponding, in every particular, with the phænomena in question? Let L M (fig 3.) represent the level of the ocean, with the moon vertical at $M$, or, rather, about two degrees beyond it, and $\mathrm{LH}$ the waters gradually lifted up by expansion, from the point where the moon has no influence to the point where her influence is greatest. Now it is evident, that the higher the waters are raised the more rare they will become; and, as the denser parts of the fluid must necessarily press upon the rarer, the pressure produced in this way will occasion an additional rise on the one side and a corresponding fall on the other. Here, Sir, you will observe, that there is no impediment to prevent this pressure from taking effect, because the waters actually do become rarer, and the pressure takes place at the same moment with the expansion. The dotted line $l h$, in the above figure, represents the elevation and fall produced by this pressure ; and, though it may be difficult, if not impossible, to calculate the exact proportion, it is evident that the elevation will be so much greater than the fall, as the waters are lifted up in the first place by expansion, independently of pressure.

Now, Sir, suppose you had occasion to pass through a wild and intricate country, where you had never travelled before: it is possible that a stranger might put you in the right road by accident; but if there were a great number of subsequent turnings, your guide could not always go right, unless he was well acquainted with the way; and, by the same rule, if my theory was false, it might, by pure accident, agree with one or two isolated facts; but it is impossible that it could so entirely coincide with all the most minute phænomena, unless these phænomena 
were produced by the very cause I have assigned. Search the records of philosophy from the earliest periods, and where will you find any thing like this? Where will you find an instance of a false theory in which no one can point out an error? And yet, while you refuse to admit my theory, you attribute such a miracle to me. You cannot say that my theory does not satisfactorily account for all the phænomena connected with the rising of the tides; and the only objection you can possibly make to it is, that the principle is inadequate an objection, begging your pardon, which is founded in your own ignorance of the rate by which the power of gravity diminishes. If you will have it " that the power of gravity decreases as the square of the distance increases," then the power of the moon's attraction, at the earth's surface, can only amount to the 144-thousandth* part of the earth's, and a pressure derived from this force can only produce a rise and fall equal to the 144-thousandth part of the ocean's depth. Supposing the ocean to be twenty miles deep, and allowing it the full breadth of $90^{\circ}$, it will not produce a rise and fall of nine inches; and we want a principle that will raise the waters four or five fathoms. Choose what principle you will, you cannot make it answer, unless you give up this pretended law, which you know very well has no existence in fact; and if you cannot tell in what proportion the power of gravity decreases with the increase of distance, how can you make it an argument, that the power of the moon's attraction is not quite sufficient to produce the effects my theory requires?

In my last pamphlet I proved, in the first place, that the power of gravity does not decrease as the square of the distance increases; for, if it did, the sun's attraction at the earth's surface would be fifty times greater than the moon's: and secondly, that the moon's attraction at the earth's surface might possibly be equal to the 50th part of the earth's, and, in all probability, is equal to the 100dth: and, supposing the moon's attraction in our latitudes to be equal to the 200 dth part of the earth's, seven or eight $\dagger$ miles depth of ocean would be quite sufficient to produce the necessary expansion.

* In the latitude where, according to your and Laplace's theories, the original tides are produced, it can only amount to the 280 -thousandth part of the earth's attraction.

+ It is evident by Mr. Perkins's two experiments, that the degree of the compressibility of water increases in arithmetical proportion with increased depth ; and consequently, twice the depth of ocean will produce a four-fold rise. Supposing the moon's attraction at the surface of the earth to be equal to the 200 dth part of the earth's, seven or eight miles depth would produce a rise and fall of nearly five fathoms; and, if it should only equal the 800dth part of the earth's attraction, a depthi of fourteen or fifteen miles would raise 
If you will not allow the power of the moon's attraction at the earth's surface to be so much as my theory recquires, you at least cannot prove that it is not; and, in that case, the only fair way to determine the question is to ascertain which of the two theories comes nearest the truth. By comparing the difference between the high-water marks at spring and neap tides, with the difference between the low-water marks, it is easy to ascertain what proportion the elevation bears to the fall. Now, if there should be no difference between the rise and the fall, it will be evident that the tides must be produced by pressure, and not by expansion; if the elevation should exceed the fall in a very trifling degree, the effect produced by expansion must be equally trifling; but if; as I believe is the case, the elevation should be twice as great as the fall, it must be evident that one-half of the elevation is produced by expansion alone, for there is no other principle that will produce this effect; and, as the rise of the other half, with its corresponding fall, must be nearly, if not entirely, produced by a pressure, which is the necessary consequence of this expansion, it follows that the pressure of the waters, which is solcly dependent upon a difference in the gravity of their particles, has either produced no effect whatever, or, at the utmost, an elevation and fall which are too trifling to deserve any consideration.

Bath, March 12, 1823.

Waltr Fomman.

\section{Notices respecting New Books.}

"A Table of the Crrcles, arising fiom the Drvision of a Unit, or any other wohole Number, by all the Integers from 1 to 1024; being all the pure decimal QuoTIENT's that can arise from this Source:" 8vo. pp. 118.

"A Tabular Series of Decmal Quotients, for all the proper vulgar Fractions, of which when in their lowest Terms, neither the Numerator nor the Denominator is greater than 1000 :" 8vo. pp. 153.

IN our 47th volume, p. 385, and in our 51 st volume, p. 137, we have briefly noticed the ingenious and vastly laborious calculations of Herry Goodwyn, Esq. on the subject now further prosecuted by the same gentleman, in the works before us. 'The first of the thin volumes entitled as above, contains all

the waters to the same height. As philosophers can neither prove, on the one hand, that the deep parts of the ocean do not ever excecd fifteen miles, nor, on the other, that the moon's attraction at the earth's surface may not be equal to the fiftieth part of the earth's, I cannot understand upon what principle they found their objections to my theory.

requisite 